\title{
LA OBRA DE ARTE COMO VIRTUALIDAD \\ DESDE LA PERSPECTIVA HERMENÉUTICA
}

\author{
Antonio GuTIERrEz Pozo \\ Universidad de Sevilla
}

\section{La obra de arte como virtualidad}

Debido a la vertiginosa expansión de las denominadas «nuevas tecnologías» hoy estamos experimentando una especie de apropiación tecnológica de la realidad virtual, como si fuera un descubrimiento de nuestro informatizado y «enred-ado» (en internet) mundo. No obstante, el término "virtual» procede del latín virtus, es decir, la fuerza o virtud que posee la capacidad de producir un efecto aunque no lo produzca en el presente. De este carácter potencial de la virtus procede el significado de "virtual» como implícito o tácito, y también su comprensión como existencia aparente y no real, frente a la existencia efectiva y real. Este último sentido es el que ha dominado en la tradición filosófica, y el que han explorado las nuevas tecnologías actuales, pero también es el que cayó prisionero de la dialéctica platónica del enfrentamiento entre ser y apariencia, que despojaba a lo aparente/virtual de toda relevancia ontológica y lo relegaba a trasunto de valor secundario respecto de lo real. Hoy, según Jaron Lanier, se entiende por «realidad virtual» tanto la simulación por ordenador de distintos procesos que se presentan en los variados ámbitos de la realidad -física, social, biológica, etc.- como la invención de nuevos fenómenos y procesos perceptivos ${ }^{1}$. Desde luego el uso reiterado e insistente en la actualidad de la expresión "realidad virtual" casi podría sugerir la conversión de la dimensión de la realidad virtual en un invento de las nuevas tecnologías. Pero tal vez más adelante podamos comprender que esa misma insistencia es sospechosa.

1 Apud J. Echeverría, "Virtualidad y grados de realidad", Daimon. Revista de filosofia, 24 (2001), p. 23. 
Es indudable que la nueva tecnología ha logrado una impresionante extensión del fenómeno virtual en nuestra vida cotidiana, posibilitando incluso la creación de nuevas formas de relaciones interpersonales - las comunidades virtuales de H. Rheingold ${ }^{2}-$, y haciendo de rebote de lo virtual un tema esencial en la reflexión filosófica y estética contemporánea. Pero verdaderamente siempre el ser humano ha estado pendiente de lo virtual e imaginario, y siempre esta dimensión irreal de lo existente ha sido objeto de la reflexión. Y no sólo eso. No es casual que en la inagotable metáfora que está en el origen de la filosoffa, y que en cierto modo persiste en el fondo de nuestro pensar y existir, en el mito de la caverna platónica, esté planteado este problema de modo central, aunque en este caso sea para rebajar la trascendencia ontológica de lo virtual: para Platón los hombres que se dejan vivir, que existen en actitud natural y no practican el esfuerzo cognoscitivo y ético- de liberarse de las cadenas que les atan al mundo natural, sólo conocen virtualidades, sombras, no la verdadera realidad. Ahora bien, también es cierto que hoy la reflexión sobre lo virtual tiene el interés práctico-actual de hablar de modo esencial del hombre contemporáneo, tal vez más prisionero de lo virtual que nunca. El fenómeno virtual es tan antiguo como el propio hombre, y cabe preguntarse si puede haber ser humano sin que exista virtualidad. Desde luego el hombre siempre ha producido virtualidad, «realidad irreal». No hay verdaderamente ser humano hasta que no crea virtualidad. Con el hombre, nació la realidad virtual. Lo propio del ser humano es la creación - junto y sobre la realidad que ya está ahí, la "materia» - de universos imaginarios o virtuales - lo «ideal». El hombre es el animal fantástico, y la cultura toda es el inmenso orbe de la virtualidad. El ser humano, ciudadano de dos mundos, animal bidimensional y naturaleza fronteriza, vive entre esas dos regiones, con un pie en la realidad y otro en la virtualidad. El Quijote cervantino parece sugerirnos en clave estética esta tesis antropológica. El hombre ni es el cura, el barbero o el bachiller Sansón Carrasco, ni es Don Quijote. Unos, apegados a la realidad, y el otro a la virtualidad. Para los primeros, ciegos para lo virtual y lo ideal, el universo se reduce a lo que ya hay y está ahí, pero para el segundo, sin sentido adecuado de lo virtual, la realidad no es otra cosa que la virtualidad. Lo humano, insinúa Cervantes, es reconocer lo virtual que subyace en la profundidad de la realidad, pero reconociéndolo desde luego como virtualidad o idealidad y no como realidad efectiva.

${ }^{2}$ Cfr. H. Rheingold, The virtual community, Reading, Addison Wesley, 1993 (ed. esp. de J. A. Álvarez, Barcelona, Gedisa, 1996). 
Esta antropología estética permite a Cervantes avanzar en una dirección que podemos calificar de ontológica y que resulta del máximo interés para nuestra reflexión sobre lo virtual. Precisamente porque el hombre existe en la frontera entre esos dos universos - real y virtual-, Cervantes da un paso adelante más allá del dualismo de Platón proponiendo la confusión de los dos mundos - y lo mismo hará luego Unamuno en Niebla o Abel Sánchez. Cuando el cura y el barbero - recordemos - revisan la biblioteca de Don Quijote examinan curiosamente la Galatea del propio Cervantes y descubrimos entonces que el barbero es su amigo, y no tiene precisamente un alto concepto de él ${ }^{3}$. No olvidemos tampoco que en la segunda parte los protagonistas del libro han leído ya la primera parte del Quijote. Este trasiego entre lo real y lo virtual, entre el mundo (real) del lector y el mundo (virtual) del libro, nos advierte, en primer lugar, de que la realidad no es una presencia cerrada, como suponían el cura o el barbero cervantinos, sino que incluye lo virtual, lo que por tanto implica afirmar la realidad de la virtualidad. Esta riqueza inagotable de la realidad, entendida ya como tesoro de virtualidad, está expuesta por el propio Cervantes cuando Don Quijote le dice a Sancho que "eso que a ti te parece bacía de barbero, me parece a mí el yelmo de Mambrino, y a otro le parecerá otra cosa" ${ }^{4}$. Pero además, en segundo lugar, esa fusión tiene una lectura más inquietante: igual que nos advierte acerca de la realidad de lo virtual, nos sugiere el carácter virtual o ficticio que tenemos nosotros y nuestro mundo real. Si los personajes de la ficción pueden ser lectores de su propia ficción y ejercer como personas reales, nosotros, los lectores reales del libro, también podemos ser personajes de ficción.

La metáfora cervantina no sólo enseña el lugar fronterizo que ocupa el hombre, y la confusión entre los universos real y virtual - aparentemente disparesque de esa posición límite del hombre se desprende. También enseña específicamente lo que es el arte, esa delicada y exquisita virtualidad que es la obra de arte, el objeto estético. En concreto, los capítulos veinticinco y veintiseis de la segunda parte del Quijote, los dedicados al retablo de Maese Pedro, son verdaderamente todo un tratado (more estético) de estética. En estos capítulos la obra cervantina reflexiona sobre sí y en general sobre el objeto virtual que representa la obra de arte, introduciendo dentro de la virtualidad que es el libro otro objeto estético y virtual: el retablo. La falta de educación estética de Don Quijote, que le lleva a

\footnotetext{
${ }^{3}$ Cervantes, Quijote, I, 6.

4 Quijote, I, 25.
} 
intervenir en la escena virtual que en el retablo se desarrolla ante él como si fuera realidad, pone de manifiesto que la obra de arte no es realidad y que por tanto no puede ser tratada con la misma actitud (natural) con que vivimos el resto de la vida, sino con "sentido estético", el que le falta a Don Quijote, y que no es otra cosa que sentido para lo virtual. El arte aumenta o enriquece la realidad lo que ya está ahí por sí mismo- ańadien'do la virtualidad estética, una irrealidad. Pero también Don Quijote parece hacerlo en principio: donde hay realmente molinos él ve gigantes. Ahora bien, Don Quijote no es modelo de artista porque no le añade al molino su ser gigante virtualmente sino realmente. No añade ni enriquece la realidad: para él realmente hay gigantes. Don Quijote no es un artista porque le falta el sentido para lo virtual, el sentido para reconocer lo virtual como tal, y dado que la obra de arte es una región de irrealidad o virtualidad, un mundo sutil, ingrávido y gentil, como una pompa de jabón, según poetizaba Machado, el sentido para lo virtual es condición indispensable tanto para crearla como para experimentarla. El artista, en cambio, es Cervantes: él sí ha descubierto la potencialidad estética (virtual) que tienen los molinos de volverse (virtual, irreal, ideal o metafóricamente) en gigantes. Lo propio del artista es el descubrimiento de esas posibilidades virtuales de lo real, es decir, la transfiguración estética o virtual de lo real; y lo propio del espectador es experimentar esas virtualidades en tanto que tales. La realidad es tan rica - tan poco realidad en el sentido en que la entendían el cura y el barbero- que incluye en sí misma esas dos obras de arte: el retablo de maese Pedro y el propio libro cervantino, espacios virtuales rodeados de realidad, sea la realidad de la venta interior al libro, o la realidad del mundo del lector que rodea al libro. Lo esencial es que son virtualidad incrustada - injertada - en la realidad. Y por extensión, virtualidad es la cultura toda. En Las Meninas de Velázquez encontramos un fenómeno estético semejante al que plantea Cervantes en los capítulos del retablo. El cuadro que pinta Velázquez en Las Meninas es el equivalente del retablo de maese Pedro, y el taller del artista - la realidad en la que se halla el cuadro- es el paralelo de la venta manchega. Ambos, cuadro y taller, forman parte de la virtualidad que es la obra velazqueña - trasunto del libro de Cervantes - y que se encuentra rodeada del mundo real y cambiante de los espectadores. Lo que en definitiva enseña Cervantes es a superar el horizonte tradicional de comprensión de la obra de arte: la oposición arte/naturaleza o, en un lenguaje más actual, apariencia/realidad.

Es evidente que la categoría de lo virtual tiene un puesto central en la estética. Ciertamente, no todo lo virtual es estético, pero lo estético sí que tiene que 
ver esencialmente con lo virtual. La comparación de la experiencia estética con la descripción fenomenológica de la epokhé nos va a servir de hilo conductor para introducirnos en el ser del arte. Mientras vivo, sin más, mientras existo en el natural dejarme vivir, no hay para mí "conciencia de" la realidad, sino que justamente hay «realidad». La conciencia natural está volcada sobre el mundo y experimento su pesada realidad. Al practicar la epokbé, asegura Husserl, hemos "puesto entre paréntesis» o "desconectado" el mundo real o natural. Nada ha cambiado, el mundo epokbeado es el mismo mundo real, pero - eso sí- desconectado, desrealizado, reducido a nóema, a lo que es pura y primariamente para la conciencia pura ${ }^{5}$. Tras la epokhé lo que hay es el mundo reducido a objetividad primaria, la realidad reducida a su "conciencia de". Ahora bien, escribe Husserl, el árbol reducido, la «conciencia de" árbol, no arde, es un árbol virtual o ideal, la imagen (pura o trascendental para Husserl) de árbol ${ }^{6}$. Efectivamente la conciencia o imagen del dolor no duele; es dolor virtual, mientras que el dolor real y efectivo es lo contrario de su imagen virtual. Pero el mundo epokheado guarda cierto parecido con el objeto estético: el árbol pintado o poetizado tampoco arde, también es un árbol virtual. Por esto pudo decir Husserl que en el arte se verifica una "reducción eidética cumplida espontáneamente (spontan erfüllt)», o sea, de naturaleza estética y no reflexivo/teorética ${ }^{7}$. En el arte se practica more estético lo mismo que en la filosofía: la desrealización y constitución de un ámbito de virtualidad. De ahí también que la experiencia estética presente una conexión tan sugerente con la práctica de la epokhé fenomenológica. Cuando se apagan las luces del cine, se sube el telón del teatro o abrimos el libro y empezamos a leer, rompemos los nexos que nos mantenían unidos al mundo real, nos desconectamos de él y nos adentramos entonces en un universo virtual, irreal, la región del

${ }^{5}$ E. Husserl, Ideen zu einer reinen Phänomenologie und phänomenologische Philosophie, Husserliana III/1, her. v. K. Schuhmann, Den Haag, Nijhoff, 1976, \$97, pp. 225s (ed. esp. de J. Gaos, México, FCE, 1985, p. 236). Es más, según Husserl, no sólo no hemos perdido nada sino que hemos ganado el «íntegro ser absoluto» (Id., $\$ 50$, p. 107; ed. esp., pp. 115s).

${ }^{6}$ Id., $\$ 89$, p. 205 (ed. esp., p. 216). Contra cualquier posibilidad de interpretación subjetivista o psicologista, Husserl añade que ese árbol virtual no es mero producto psíquico, y que es tan poco ingrediente de la percepción como lo es el árbol real. Verdaderamente es una objetividad, pero no real, desde luego, sino intencional - -virtual», diríamos nosotros. En esta tesis husserliana está perfilada la posterior afirmación gadameriana — contra todo resto de subjetivismo estético-de que la imagen pertenece al ser.

"Apud O. Becker, cfr. H-G. Gadamer, "Philosophie und Literatur" (1981), Gesammelte Werke, Band 8, Tübingen, J. C. B. Mohr (Paul Siebeck), 1993, p. 255 (ed. esp. de A. Gómez, Estética y hermenéutica, Madrid, Tecnos, 1996, p. 199). 
arte. Ahora bien, para lograr penetrar en ese delicado mundo virtual tengo que suspender mi vida real, mi realidad, y absorberme en el mundo mágico de la obra. Sin adoptar esa actitud no podremos entrar en la irrealidad de la obra. Tener sentido para lo virtual es la condición indispensable para ser un buen lector o espectador del arte.

Pero el carácter esencialmente virtual de lo artístico no significa que sea una mentira o falsedad. La virtualidad de lo estético de ninguna manera lo convierte en enemigo de la verdad. No obstante, encontramos a veces verdad y virtualidad enfrentados. Para Nietzsche el arte es ficción e irrealidad, "santificación de la mentira y voluntad de apariencia” ${ }^{8}$. Ahora bien, precisamente por ser irrealidad, "el arte - escribe Nietzsche - vale más que la verdad" ${ }^{9}$. Y es que ese arte como ilusión es el que desea la vida para protegerse de la trágica verdad, porque "la vida quiere ficción, vive de la ficción" ${ }^{10}$. Para Heidegger, en cambio, el arte no es que sea una manifestación de la verdad de las cosas sino que —más aúnes el mismo "ponerse en obra de la verdad de lo ente (sich-ins-Werk-Setzen der Wahrheit des Seienden)" ${ }^{1}$. Sin embargo, en este tratamiento ontológico de la obra de arte que presenta Heidegger no hay ninguna referencia a algo que parece tan esencial a lo artístico como es la virtualidad, como si la introducción de esta dimensión estética virtual fuese en detrimento de la concepción ontológica del arte, es decir, como si la virtualidad estética estuviese enfrentada al carácter ontológico-veritativo del arte y fuesen inconciliables. Aunque opuestas, las posiciones de Nietzsche y Heidegger parecen coincidir en oponer y enfrentar la verdad de lo real y lo virtual, el ser y la apariencia, la vieja y tradicional oposición de raigambre platónica. Frente a esas dos posturas, en la estética de Gadamer podemos encontrar elementos suficientes para mostrar cómo la ficción estética no

${ }^{8}$ F. Nietzsche, Genealogie der Moral, III, $\$ 25$, Sämtliche Werke. Kritische Studienausgabe in 15 Bänden, Band 5, her. v. G. Colli und M. Montinari, München, Deutscher Taschenbuch Verlag/De Gruyter, 1980, p. 402 (ed. esp. de A. Sánchez, Madrid, Alianza, 1980, p. 176).

9 Nietzsche, Nachgelassene Fragmente 1887-1889, KSA, Bd. 13, p. 227 (fr. 14 [21]), p. 522 (fr. 17 [3]) (ed. esp. de A. Izquierdo, Estética y teoría de las artes, Madrid, Tecnos, 1999, pp. 77, 178).

${ }_{10}$ Nietzsche, Menschliches, Allzumenschliches, Erster Band, Vorrede 1, KSA, Bd. 2, p. 14 (ed. esp. de A. Brotons, Madrid, Akal, 2001, v. 1, p. 36).

${ }^{11}$ Heidegger, Der Ursprung des Kunstwerkes, Holzwege, Gesamtausgabe, Band 5, Frankfurt a. M., V. Klostermann, 1977, pp. 25, 58s, 64, 67 (ed. esp. de H. Cortés y A. Leyte, Caminos de bosque, Madrid, Alianza, 1997, pp. 28, 61s, 66, 70). 
supone un descuido de la verdad de lo real sino más bien lo contrario: el rodeo por lo virtual parece el camino más adecuado para llegar a explorar la verdad. El carácter fantástico del hombre encuentra aquí una inesperada legitimación: el hombre es el animal que produce virtualidades porque lo virtual se presenta como el medio idóneo para acceder a la verdad de la realidad. Lo que aprendemos de Gadamer es la voluntad de darle carácter ontológico al arte sin renegar de su virtualidad. Ahora bien, este reconocimiento de la relevancia ontológica de lo virtual no puede hacerse sin ampliar el concepto tradicional de lo real -lo que ya está ahí por sí mismo- en dirección virtual. Volvemos pues a encontrarnos con el trasiego cervantino entre realidad y ficción o virtualidad. Kundera escribe que el legado de Cervantes, la novela, la otra cara de la modernidad, una posibilidad latente no transitada por la modernidad oficial de corte más cartesiano, es "el paraíso imaginario de los individuos (...) el fascinante espacio imaginario en el que nadie posee la verdad y todos el derecho a ser entendidos" ${ }^{12}$. Tal vez le falte a Kundera insistir en el planteamiento cervantino de la fusión entre realidad y virtualidad como otra posibilidad de la modernidad. También con ello Cervantes fue algo más allá de Descartes, cuyo empeño principal - y para lo cual no dudó en apelar al mismo dios bueno y veraz- no era otro que demostrar que las cosas, además de virtualidades o ficciones, esto es, además de cogitata, de presencia inmediatas en mi conciencia, eran realidades, cosas en sl, empeño que volvía a dejar de manifiesto tanto el enfrentamiento de base entre lo real y lo virtual, el ser y la apariencia (Schein), como la primacía sustancialista o naturalista de lo real, libre por supuesto de toda virtualidad.

\section{La relevancia ontológica de la virtualidad estética}

La dilatación del concepto de lo real que permitiría la acogida en su seno de lo virtual supone la quiebra de la dialéctica platónica del enfrentamiento entre realidad y virtualidad. Ahora bien, no cualquier virtualidad tiene dimensión ontológica. Esto ocurre sólo según Gadamer en la virtualidad estética. El camino que recorre Gadamer pretende conciliar la relevancia ontológica del arte expuesta por Heidegger con el reconocimiento de la virtualidad de la representación artística. Lo que Gadamer pretende desterrar ante todo es lo que él mismo llama «distinción estética (ästhetische Unterscheidung)", es decir, la diferencia y contraposición

${ }^{12}$ M. Kundera, El arte de la novela, Barcelona, Tusquets, 1987, pp. 14, 175, 180 s. 
de naturaleza platónica entre el mundo virtual del arte determinado ontológicamente como mundo de la apariencia y el mundo real, contraposición que se fundamenta sobre el dominio total del modelo de conocimiento científico-natural y la consecuente desacreditación de otros modos de conocimiento - como el estético $^{13}$. Ahora bien, y esto es lo fundamental, el peso ontológico de la virtualidad estética y por tanto la ruptura de la tradicional dialéctica platónica entre realidad y apariencia —en suma: la «no-distinción estética (die ästhetische Nichtunterscheidung) "-, dependen de que -con Gadamer - comprendamos que la obra de arte no es una representación en el sentido de reproducción o copia (Abbila) del mundo, como si se tratase de un producto de la conciencia, un contenido de conciencia. Más bien, la obra de arte es representación en el sentido -ontológicamente relevante- de que es un modo nuevo de presentación del mundo ${ }^{14}$. Gadamer nos invita a superar la comprensión tradicional de lo estético que — desde la oposición entre realidad y apariencia — lo piensa partiendo de la realidad para entenderlo finalmente como ámbito de la belleza, como una región ideal donde se trascienden los límites de lo real, o sea, como una modificación (y/o apariencia) de la «auténtica realidad». Al comprender lo estético como «imitación», «apariencia (Schein)», «desrealización", «ilusión» o «encantamiento (Zauber)", se presupone desde luego la existencia de un "ser auténtico (eigentliches Sein)» del que aquél sería distinto ${ }^{15}$. La representación estética ni es mera copia aparente o virtual respecto de la supuesta realidad verdadera y en sí, ni es

${ }^{13}$ Gadamer, Wahrheit und methode. Hermeneutik I (1960), GW, Bd. 1, 1990, p. 91 (ed. esp. de A. Agud y R. de Agapito, Verdad y método, I, Salamanca, Sígueme, 1977, pp. 125s). Es indudable que la superación del enfrentamiento entre ser y apariencia, que primaba al ser y relegaba a la apariencia al plano ontológico secundario, y por tanto la reivindicación de la apariencia sensible, se encuentran ya iniciadas por Hegel, y precisamente en el campo estético. Este es el sentido de su comprensión de lo bello como "manifestación sensible de la idea (sinnliche Scheinen der Idee)", tesis no por casualidad tan destacada por Gadamer (G. W. F. Hegel, Vorlesungen über die Ästhetik (1820-1829), Werke, I, Band 13, Frankfurt a. M., Suhrkamp, 1986, p. 151; ed. esp. de A. Llanos en 8 vols., Buenos Aires, Siglo Veinte, 1985, v. 2, p. 47). La presencia de lo absoluto en lo sensible y aparente (Erscheinenden) defendida por Hegel, y la lógica conciliación entre ambas dimensiones, experiencia que se produce en lo bello, en la virtualidad estética, nos enseñan el camino de la valoración de la apariencia, de lo virtual (Id., Werke, III, Bd. 15, p. 573; ed. esp., v. 8, p. 319).

14 Id., p. 122 (ed. esp., p. 162). Gadamer recoge aquil la crítica heideggeriana al concepto moderno de lo estético, que consiste en la comprensión reductora del arte a vivencia subjetiva, a objeto de la "conciencia estética". Siguiendo a Heidegger, el arte sólo podrá tener relevancia ontológica una vez liberado de la "distinción estérica" que abstrae el puro elemento estérico y lo aparta del ser (cfr. Gadamer, Wahrheit und methode, p. 91 (ed. esp., p. 125).

15 Gadamer, Wabrheit und methode, p. 89 (ed. esp., p. 123.). 
su desviación encantadora, sino que tiene una vinculación ontológica con ella. La representación virtual estética no es ya mera "representación»: no está realmente -ontológicamente- separada de lo que representa, sino que pertenece al ser mismo de lo representado.

A diferencia de lo que suponía la distinción estética, que abstraía precisamente esta presencia del original en la imagen o representación, el núcleo ontológico de la hermenéutica reside en la afirmación de la indistinción entre representación (Darstellung) y lo representado (Dargestelltem), que ya no pueden entenderse more tradicional como apariencia y realidad ${ }^{16}$. La representación estética posee verdadero peso ontológico, y no es como la imagen virtual del espejo, que - separada de lo representado - no participa de su ser, razón por la cual pasamos a través de ella para llegar al objeto representado, sin reparar desde luego en ella misma porque nada dice de lo representado ${ }^{17}$. La virtualidad estética no es una simple ilustración de una realidad ya dada y a la que en último término se referiría, sino la existencia de esa misma realidad ${ }^{18}$. Esto significa que la realidad no acaba en ella sino que continúa en la virtualidad estética, cuyo carácter representacional significa ante todo según Gadamer un "incremento de ser (Zuwachs an Sein)" de la propia realidad ${ }^{19}$. Gadamer rompe así con la tópica oposición platónica que ha dominado en parte la tradición filosófica entre ser y apariencia, realidad y virtualidad, original y copia. Las copias ya no son meras apariencias virtuales de lo verdaderamente real, sino su interpretación, o sea, su enriquecimiento virtual o potencial. La virtualidad estética forma parte de lo real y muestra el rango ontológico que poseen las apariencias. Lo que la ontología hermenéutica condena en definitiva es la afirmación de una supuesta realidad en sí que existe al margen de sus representaciones, de manera que su tesis principal es que el aparecerse, la llamada «apariencia», pertenece al ser, para dejar de ser la tradicional "apariencia» de una presencia real en sí.

16 Id., p. 144 (ed. esp., p. 188).

17 Hay otras representaciones no artísticas que no cumplen esta condición ontológica: los simbolos, consistentes en el puro estar por otra cosas, y las señales, que son el puro referirse a algo otro. Cfr. Gadamer, Wabrheit und methode, pp. 156ss (ed. esp., pp. 202ss).

${ }_{18}$ De acuerdo con Gadamer, así podría entenderse la comprensión hegeliana de lo bello como la «manifestación sensible de la idea", es decir, no como ilustración subsiguiente a la idea ya dada sino como el "aparecer» (Scheinen) —estético, sensible- de esa misma idea. Cfr. Gadamer, Wabrbeit und methode, p. 149 (ed. esp., p. 193).

${ }^{19}$ Gadamer, Wabrheit und methode, p. 145 (ed. esp., p. 189). 
Ahora bien, del mismo modo que Gadamer considera inadecuada la distinción entre realidad y virtualidad, también sostiene que ya no cabe distinguir contra el tópico de la realidad y el sentido originarios- entre la obra de arte original en sí misma y sus interpretaciones - sean las interpretaciones que formulan los lectores de un libro o los espectadores de un cuadro, sean las interpretaciones de una partitura musical o de una pieza teatral. Las interpretaciones están en el mismo plano ontológico respecto de la obra que lo virtual estético respecto de la realidad: son posibilidades de ser propias de la obra ${ }^{20}$. No hay la «única y verdadera» representación o interpretación correcta de una obra, como tampoco hay una realidad en sí al margen de sus manifestaciones o ampliaciones virtuales. Igual que hay una virtualidad respecto de una realidad formando parte de ella y sin distinción, también hay un espacio ontológico de virtualidad respecto de la obra de arte "original» debido a sus intérpretes. Desde este horizonte cabe interpretar la comprensión de la novela expuesta por R. Ingarden. Según él, la fuerza de evocación de la novela es tal que, por muy minuciosa que sea en la relación de detalles y a pesar de que lo descrito es lo mismo, la novela es rellenada - virtualmente- por cada lector de un modo diverso. La novela - toda obra de arte en general - libera un espacio de juego (virtual) de posibilidades de actualización real que no son meras apariencias de la verdad o realidad de la obra, sino que están integradas en ella ${ }^{21}$. Lo evocado mediante las palabras posee una suerte de virtualidad que forma parte de la realidad de la novela, de manera que puede decirse que la novela no tiene una realidad en sí frente a sus interpretaciones virtuales, sino que su realidad es todo ese juego de evocaciones virtuales que suscita.

Podemos pensar que la virtualidad estética tiene en lo real su punto de partida, pero a partir de aquí no se la puede entender ya en clave platónica como alejamiento de lo real verdadero, simple apariencia; más bien, Gadamer considera que la realidad es eso que lo virtual construye. Contra el mito del original y de lo originario, y en definitiva contra la comprensión de la virtualidad estética como añadido o variación respecto de una realidad ya dada, Gadamer presupone - $y$ esto es esencial a la hermenéutica - que la realidad no está acabada sino que continúa haciéndose mediante la obra de arte, en lo virtual. No hay

${ }^{20}$ Id., pp. 122s (ed. esp., pp. 162s).

${ }^{21}$ Cfr. R. Ingarden, Das literarische Kunstwerk (1931), Tübingen, Max Niemeyer, 1972, $\$$ $15,16,20,38$. 
pues distinción ni contraposición entre virtualidad estética y realidad. La realidad se actualiza - interpreta - en sus representaciones virtuales y no existe verdaderamente al margen de éstas. «En la obra de arte, escribe, no sólo algo es referido (verwiesen ist), sino que en ella está auténticamente (eigentlicher) aquello a que se refiere» ${ }^{22}$, y esta es la razón de que la obra, primero, suponga un incremento del ser, y segundo, siga siendo irreemplazable incluso en la época de su reproducibilidad técnica. Efectivamente, como ocurre en el juego infantil, no puede hacerse una distinción entre los niños $-o$ los actores de una pieza teatral-y lo que ellos representan, entre la apariencia y la supuesta realidad. Por esto Gadamer puede comprender la obra de arte como "transformación en una construcción (Verwandlung ins Gebilde)", es decir, en un mundo cerrado que tiene su patrón en sí y que no puede medirse por nada exterior a él, p. e., por una supuesta verdadera realidad de la que ella sería su mera «representación» o copia ${ }^{23}$.

Sin duda, en esta dirección hay que entender también la afirmación heideggeriana de la obra de arte como puesta en obra de la verdad. Ahí Heidegger quiere decir que la obra no es reflejo de un ser o realidad que represente la verdad, desde la cual habría que medir a la propia obra, sino que ésta misma es la verdad. De aquí se desprende que no podemos hablar de "verdad" o "falsedad" estéticas en virtud de un referente objetivo y exterior a la obra desde el cual valorarla, pues realmente nada hay a lo que la obra de arte tenga que adecuarse. La verdad y falsedad estéricas se refieren única y exclusivamente a la propia obra. Una obra de arte es verdadera, podemos decir parafraseando a Gadamer, cuando no sólo remite a algo, sino cuando en ella está propiamente aquello a que se remite. La falsedad estética no reside pues en el hecho de que la obra no se corresponda con una determinada realidad (material o ideal), sino en el hecho de que no desvele o manifieste algo, es decir, cuando no pone nada delante, cuando no hace ver. En este sentido toda verdadera obra de arte es alétheia. Desde esta perspectiva, la estética hermenéutica gadameriana representa una revaloración del concepto de mímesis, relegado en la modernidad, tal vez porque ha sido injustamente interpretado en clave naturalista radical como simple reproducción. La virtualidad estética es mimética no porque reproduzca o copie lo real sino porque como enriquecimiento de lo real representa la transformación de la realidad

${ }^{22}$ Gadamer, Die Aktualität des Schönen. Kunst als Spiel, Symbol und Fest (1974), GW, Bd. 8, p. 126 (ed. esp. de A. Gómez, Barcelona, Paidós/ICE-UAB, 1991, p. 91).

${ }^{23}$ Gadamer, Wabrheit und methode, pp. 116s (ed. esp., pp. 154ss). 
hacia su verdad y por tanto la superación (Aufhebung) de esa realidad no transfigurada, de modo que la realidad - lo que llamamos "realidad" — es "lo no transformado (das Unverwandelte) ${ }^{24}$. El mundo que aparece en la virtualidad estética no es una simple copia del mundo real, sino que es este mismo mundo pero en la "acrecentada verdad de su ser (gesteigerten Wabrheit ihres Seins)" ${ }^{25}$. En el arte está la misma realidad pero virtualmente desrealizada, o sea, liberada de sus factores contingentes y reducida a su verdadero ser. La virtualidad estética no es la realidad, pero sí es la plenitud de lo real.

La mímesis pues no es mera copia sino acontecimiento ontológico, pero además lo es no sólo porque tiene que ver con el «ser», sino sobre todo porque en tanto que transmutación de la realidad en su verdadero ser- representa el "poder ser». Tal es el poder crítico de la virtualidad estética. El arte no sólo nos dice "eso eres tú (Das bist du)», recuerda Gadamer; también y especialmente nos está diciendo "debes cambiar tu vida (Du mußt dein Leben ändern) " ${ }^{26}$. Efectivamente la virtualidad estética supone un momento mimético: su primer movimiento va de lo real al arte. Ahora bien, esta operación de fuga de la realidad no tiene el objetivo de quedarse en un universo ilusorio al margen de lo existente. $\mathrm{Al}$ movimiento de lo real al arte le sigue otro contrario del arte a lo real: «del texto a la acción", anuncia Ricoeur. La esencia de la obra de arte, advirtió ya Aristóteles, es mímesis y catarsis: la obra de arte afecta al espectador purificándolo de lo real, es decir, dejándolo libre frente al poder de lo existente. Si Gadamer ha criticado la distinción estética y ha afirmado la pertenencia de lo virtual estético a la realidad no es para que se reintegre plácidamente a la realidad existente y la santifique ideológicamente desde su exquisita irrealidad. La virtualidad estética representa un aumento del ser respecto de la realidad que ya está ahí en sentido crítico: esa virtualidad nos dice que lo real es insuficiente y ella misma, per se, significa la apertura de un horizonte de posibilidades que niegan y trascienden la realidad dada ${ }^{27}$. Por supuesto que la obra de arte tiene un referente, señala

${ }^{24}$ Id., p. 118 (ed. esp., p. 157).

${ }^{25}$ Id., p. 142 (ed. esp., p. 185).

${ }^{26}$ Gadamer, «Ästhetik und hermeneutik» (1964), GW, Bd. 8, p. 8 (ed. esp., Estetica y hermenéutica, p. 62).

${ }^{27}$ También Hegel se refirió a la dimensión crítico-liberadora del arte al afirmar que la experiencia estética supone una "liberación (Befreiung) del espíritu del contenido (Gehalt) y de las formas (Formen) de la finitud (Endlichkeit)" (Vorlesungen über die Ästhetik, Werke, III, Bd. 15, p. 573; ed. esp., v. 8, p. 319). 
Ricoeur, "pero, añade, este referente (référent) está en relación de ruptura con el referente del lenguaje cotidiano. Mediante la ficción, mediante la poesía, son abiertas en la realidad cotidiana nuevas posibilidades de ser en el mundo. Ficción y poesía apuntan al ser, pero ya no bajo la modalidad del ser-dado (lıêtredonné) sino bajo la modalidad del poder-ser (pouvoir-être). Por esto, la realidad cotidiana es metamorfoseada merced a lo que podría llamarse las variaciones imaginativas que la literatura opera sobre lo real ${ }^{28}$. Este es el papel exacto de lo virtual estético. Forma parte del ser de lo real, pero precisamente para insertar en él una segunda dimensión y abrir una confrontación sana e inevitable entre lo real y lo imaginario. Por esto es necesario mantener lo virtual, ficticio, ideal o ilusorio del arte, porque sólo entonces el arte representa un incremento crítico de lo existente.

Ahora bien, a pesar de la insistencia de las nuevas tecnologías en la tan cacareada "realidad virtual" y a pesar de sus extraordinarias posibilidades técnicas para lograr una realización de lo virtual nunca antes imaginable, o tal vez precisamente debido a ello, Baudrillard nos advierte de que con su virtualidad tecnológica lo que están consiguiendo es precisamente anular la dimensión bidimensional que debe caracterizar esencialmente a lo virtual ${ }^{29}$. La perfección técnica en la realización de lo virtual se logra al precio de perder su poder de ilusión (puissance dmillusion). Es una perfección inútil. Se perfecciona lo virtual para reproducir — virtualmente - la realidad ya dada. Lo que se busca es una simple repetición de la realidad que ya está ahí en clave virtual. La ilusión o virtualidad producida por las nuevas tecnologías es desilusionante: en ella nos volvemos a encontrar la realidad en que ya estamos. Verdaderamente es una «ficción de la realidad», en lugar de ser - como le corresponde a la auténtica virtualidad estética- la "realización o realidad de la ficción" ". Mediante la virtualidad se enmascara la realidad. El espacio de virtualidad que permitía el juego de interpretaciones al que se refería Ingarden ha desaparecido a fuerza de querer reproducir

${ }^{28}$ P. Ricoeur, Du texte à l'action, Paris, Éd. du Seuil, 1986, p. 115 (ed. esp. de P. Corona, México, FCE, 2002, pp. 107s).

${ }^{29}$ J. Baudrillard, Illusion, désillusión esthétiques, Paris, Sens \& Tonka, 1997, pp. 11 ss (ed. esp. de J. Fombona, Caracas, Monte Ávila, 1998, pp. 15ss).

${ }^{30}$ En estos términos, como realidad de la ficción, se ha referido J. L. Molinuevo a la esencia de la obra de arte. Cfr. "Estudio introductorio" a El sentimiento estético de la vida (Antología), Madrid, Tecnos, 1995, p. 35. 
virtualmente lo real: en el universo tecnológico, señala Baudrillard, la virtualidad carece de lo que la define esencialmente, esto es, de vacío (vide), de elipsis (ellipse), de silencio (silence), huecos en la realidad donde introducirse lo virtual. La virtualidad tecnológica está maciza de realidad, como el ser parmenídeo. La virtualidad deja de ser virtual en el universo de la ficción tecnológica. Esta pérdida de la ilusión estética se traduce en una glorificación de lo existente. No deja de ser curiosa la astucia ideológica de las nuevas tecnologías: para legitimar lo real nada mejor, primero, que invalidar a su gran enemigo crítico, la virtualidad, despojándolo de su poder bidimensional, y luego emplearlo paradójicamente para reproducir - y santificar de paso- lo real virtualmente, ofreciéndonos una realidad sin peso, convertida en espectáculo, como si no fuera real ... La tecnificación de lo virtual, lejos de ampliar en sentido crítico lo real, lo reproduce virtualmente con el fin de ocultar su verdadera realidad. La virtualidad tecnológica es un doble virtual de la realidad. 